\title{
The astonishing diversity of Ig classes and B cell repertoires in teleost fish
}

\section{Simon Fillatreau ${ }^{1}$, Adrien Six ${ }^{2,3}$, Susanna Magadan ${ }^{4}$, Rosario Castro $^{4}$, J. Oriol Sunyer ${ }^{5}$ and Pierre Boudinot ${ }^{4}$ *}

${ }^{1}$ Deutsches Rheuma-Forschungszentrum, Leibniz Institute, Berlin, Germany

2 UPMC Univ Paris 06, UMR 7211, "Immunology, Immunopathology, Immunotherapy," F-75013 Paris, France

${ }^{3}$ UMR 7211, "Immunology, Immunopathology, Immunotherapy," CNRS, Paris, France

${ }^{4}$ Virologie et Immunologie Moléculaires, Institut National de la Recherche Agronomique, Jouy-en-Josas, France

${ }^{5}$ Department of Pathobiology, School of Veterinary Medicine, University of Pennsylvania, Philadelphia, PA, USA

\section{Edited by:}

Harry W. Schroeder, University of

Alabama at Birmingham, USA

Reviewed by:

Michael Zemlin, Philipps University

Marburg, Germany

Peter D. Burrows, University of

Alabama at Birmingham, USA

${ }^{*}$ Correspondence:

Pierre Boudinot, Virologie et

Immunologie Moléculaires, Institut

National de la Recherche

Agronomique, Domaine de Vilvert,

78352 Jouy-en-Josas, France.

e-mail: pierre.boudinot@jouy.inra.fr
With lymphoid tissue anatomy different than mammals, and diverse adaptations to all aquatic environments, fish constitute a fascinating group of vertebrate to study the biology of B cell repertoires in a comparative perspective. Fish B lymphocytes express immunoglobulin (lg) on their surface and secrete antigen-specific antibodies in response to immune challenges. Three antibody classes have been identified in fish, namely $\operatorname{lgM}, \operatorname{lgD}$, and $\lg T$, while $\lg G$, $\lg \mathrm{A}$, and $\lg \mathrm{E}$ are absent. $\lg \mathrm{M}$ and $\lg \mathrm{D}$ have been found in all fish species analyzed, and thus seem to be primordial antibody classes. IgM and $\operatorname{lgD}$ are normally coexpressed from the same mRNA through alternative splicing, as in mammals. Tetrameric $\lg \mathrm{M}$ is the main antibody class found in serum. Some species of fish also have $\lg T$, which seems to exist only in fish and is specialized in mucosal immunity. $\operatorname{lgM} / \lg D$ and $\lg T$ are expressed by two different sub-populations of B cells. The tools available to investigate $B$ cell responses at the cellular level in fish are limited, but the progress of fish genomics has started to unravel a rich diversity of $\mathrm{lgH}$ and immunoglobulin light chain locus organization, which might be related to the succession of genome remodelings that occurred during fish evolution. Moreover, the development of deep sequencing techniques has allowed the investigation of the global features of the expressed fish B cell repertoires in zebrafish and rainbow trout, in steady state or after infection. This review provides a description of the organization of fish Ig loci, with a particular emphasis on their heterogeneity between species, and presents recent data on the structure of the expressed Ig repertoire in healthy and infected fish.

Keywords: fish, antibody, repertoire, evolution, B cells

\section{INTRODUCTION}

Teleost fish form a large zoological group with about 40,000 identified species, in comparison to 10,000 species for birds, and only around 5700 species for mammals. Fish are heterogeneous with regards to size, morphology, physiology, and behavior. They are ubiquitous throughout almost all aquatic environments, which have diverse oxygen concentrations, water pressures, temperatures, and salinities. Related representatives from the same group can be found in different ecosystems. For instance, Perciformes are adapted to both freshwater and marine habitats, including Antarctic. These diverse milieus certainly host a broad variety of pathogens. Fish can be infected by viruses (rhabdoviruses, bornaviruses, reoviruses, nodaviruses, iridoviruses, herpesviruses, etc.), bacteria (Vibrio, Aeromonas, Flavobacterium, Yersinia, Lactococcus, Mycobacterium, etc.), and many parasites. Thus, it is expected that a considerable diversity of host/pathogen interactions characterize fish immune defense mechanisms.

Most of our current knowledge on the immune systems and pathogens of fish comes from aquaculture species. In this context, pathogen diagnostic and vaccination are of considerable economic importance. As an illustration of this, the vaccination program established in Norway to protect Atlantic salmon against vibriosis and furunculosis during the last decades has dramatically reduced the impact of these pathogens, yielding a sharp increase in salmon production that now allows an export value of more than 35 billions Norwegian Kroner (close to 5 billions $€$ ) per year. The main aquaculture species of interest for immunology are rainbow trout and Atlantic salmon (Salmo salar, Salmoniformes), common, and crucian carp (Cyprinus carpio and Carassius auratus, Cypriniformes), channel catfish (Ictalurus punctatus, Siluriformes), tilapia, sea bass, and sea bream (Oreochromis niloticus, Dicentrarchus labrax, and Sparus aurata, Perciformes), Japanese flounder (Paralichthys olivaceus, Pleuronectiformes), as well as cod (Gadus morhua, Gadiformes). The immune systems of several additional species of economical importance in Asia like Grass carp (Ctenopharyngodon idella, Cypriniformes), and mandarin fish (Siniperca chuatsi, Perciformes) have been increasingly studied during the last years. In addition, a few freshwater fish species originally studied in developmental biology for their capacity to provide eggs, or for their ecological/morphological characteristics, later became experimental models in Immunology. These include 
zebrafish (Danio rerio, Cypriniformes), medaka (Oryzias latipes, Beloniformes/Cyprinodontiformes), and stickleback (Gasterosteus aculeatus, Gasterosteiformes). In sum, it stands out that our knowledge of fish immunology relates only to a minor fraction of the 40,000 known fish species. It is therefore important not to generalize observations made in individual groups, especially since our knowledge on the model species listed above already illustrates that the organization of the immune system differs among distinct fish species.

Besides its direct relevance for aquaculture, the study of the immune system of fish is also of interest to understand the evolution of the adaptive immune system in Vertebrates. The primordial adaptive immune system of extinct vertebrates is not accessible, but it can be inferred through comparative analyses of the B and $\mathrm{T}$ cell systems from distant living groups like fish and mammals. Although fish lack bone marrow and lymph nodes, fish infections by bacterial or viral pathogens can lead to the production of specific antibodies, which in some cases correlates perfectly with protection against re-infection by these pathogens. Such a protection may persist for more than 1 year. It is therefore possible to compare how the humoral immune system functions in fish and in mammals.

Research on the immune system of fish has generally been limited by the lack of reagents suitable for classical cellular immunology research, but it has greatly benefited from the sequencing of their genomes (Table 1), which have particular structural features directly relevant for their immune system. In particular, a cycle of tetraploidization and re-diploidization occurred during the early evolution of fish genomes, which was followed by further cycles of whole-genome duplications, and differential loss of various genome parts during the subsequent evolution of many fish families (Figure 1). As a result, fish genomes are especially heterogeneous. Some genes involved in the immune system have been affected by these re-modelings; in fact, the great number of gene duplicates has probably played an important role in the diversification of the immune genes through sub-functionalization and specific adaptations. This might also account for the fact that the immunoglobulin (Ig) loci of some fish species are among the largest and most complex described yet. Salmonids have two $\mathrm{IgH}$ loci per haplotype with several hundreds of $\mathrm{V}$ genes, while mammals have only one IgH loci per haplotype and fewer $\mathrm{VH}$ genes.

The availability of genomic resources has been particularly useful to investigate B cell repertoires in fish, both for the description of the genomic organization of Ig loci, which defines the potential repertoire, and for the characterization of the primary repertoire expressed by B cells in healthy and infected fish (Jerne, 1971). When considering the importance of efficient adaptive immune responses for the control of infectious diseases, and for successful vaccination, one realizes the relevance of understanding how lymphocyte repertoires are selected during $B$ cell development and modified upon antigenic challenge. In this review, we will first examine fish Ig classes, the structure of the loci, and the IgH splicing patterns. We will then study the B cell system and the features of the available (expressed) repertoires of antibodies in healthy or infected fish.

\section{DIVERSIFICATION OF IG GENES IN FISH: POTENTIAL REPERTOIRES AND DIVERSIFICATION MECHANISIMS Ig LOCI IN FISH Fish have three Ig classes}

Three classes of Ig have been identified in teleost fish. These are $\operatorname{IgM}$, which is found in all vertebrate species (reviewed in Flajnik and Kasahara, 2009), IgD, which also has a wide distribution among vertebrates, and IgT/Z (for Teleost/Zebrafish), which is specific to fish. Hereafter, fish IgM, D, and T/Z classes refer to the protein products of the isotypes $\mu, \delta$, and $\tau / \zeta$, respectively, which correspond to their associated constant genes.

IgM was the first Ig class identified in fish. It can be expressed at the surface of B cells or secreted. Secreted tetrameric IgM represents the main serum Ig in fish.

IgD was initially thought to be expressed only in rodents and primates, and to be of recent evolutionary origin. However, the first fish IgD was identified in Wilson et al. (1997) in the channel catfish.

Table 1 | Status of genome sequencing of the main model species for fish immunology.

\section{AQUACULTURE SPECIES}

Rainbow trout (Oncorhynchus mykiss)

Atlantic salmon (Salmo salar)

Atlantic cod (Gadus morhua)

Common carp (Cyprinus carpio)

Crucian carp (Carassius carassius)

Channel catfish (/ctalurus punctatus)

Tilapia (Oreochromis niloticus)

Sea bass (Dicentrarchus labrax)

Sea bream (Sparus aurata)

Japanese flounder (Paralichthys olivaceus)

\section{MODEL SPECIES}

Zebrafish (Danio rerio)

Medaka (Oryzias latipes)

Three-spined stickleback (Gasterosteus aculeatus)
Genome in progress

Genome in progress

Genome published (Star et al., 2011)

Genome published (Henkel et al., 2012)

Genome in progress

Genome available at http://www.ensembl.org/Oreochromis_niloticus/Info/Index Genome in progress

Genome available at http://www.ensembl.org/Danio_rerio/Info/Index

Genome published (Kasahara et al., 2007)

Genome published (Jones et al., 2012) 


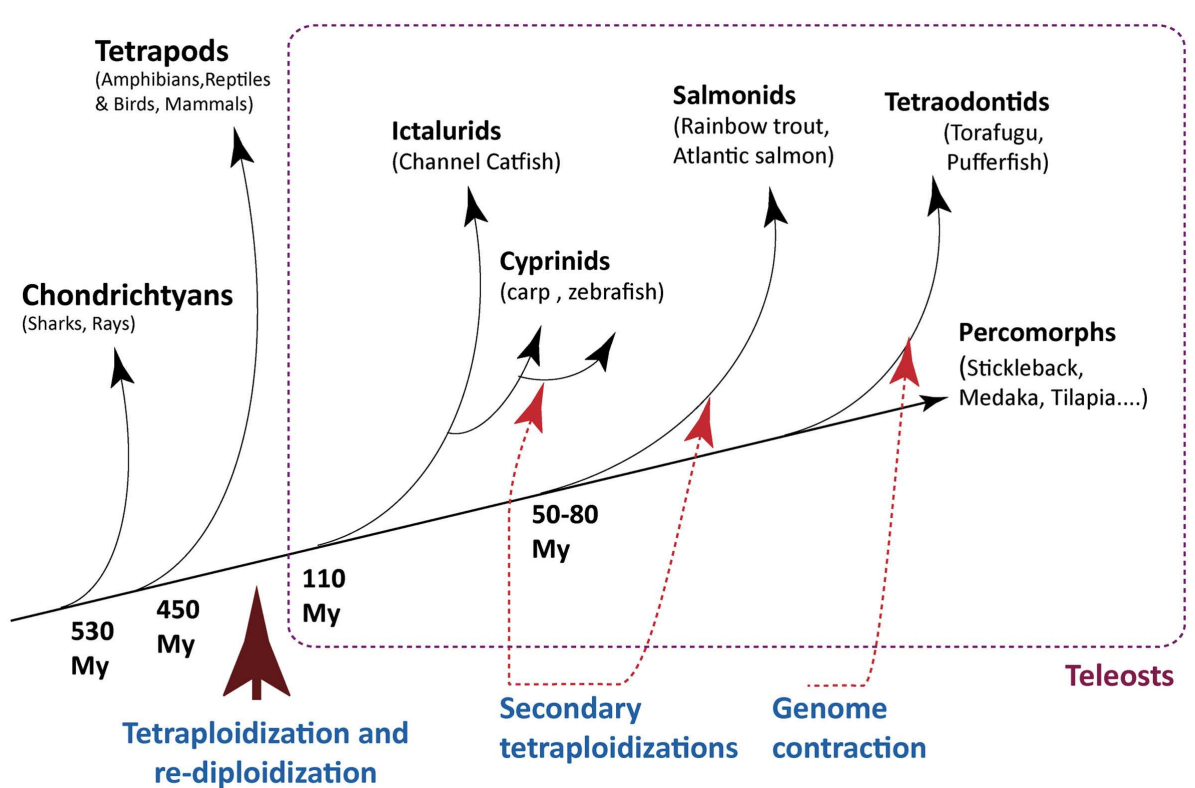

FIGURE 1 | Milestones of genome evolution within the fish lineage. A few key events of tetraploidization/re-diploidization and contraction are represented. Note that red arrows indicate a segment on the tree where an event is assumed, not a precise time point. The time arrow is not on scale.

It differs from mammalian IgD because it is a chimeric protein containing a $\mathrm{C} \mu 1$ domain followed by a number of $\mathrm{C} \delta$. This chimeric structure was also found in Atlantic salmon (Hordvik et al., 1999), and other fish species (Stenvik and Jørgensen, 2000; Aparicio et al., 2002; Hordvik, 2002; Srisapoome et al., 2004; Xiao et al., 2010). To date, no complete fish IgD heavy chain without $\mathrm{C} \mu 1$ has been described. Intriguingly, a similar $\mathrm{C} \mu 1-\mathrm{C} \delta$ structure has been discovered in some non-fish species of the order of the Artiodactyls (Zhao et al., 2002, 2003). Fish IgD also differs from eutherian IgD by the large number (7-17) of $\mathrm{C} \delta$ domains it can contain, and by the absence of a hinge. Secreted IgD have been found in catfish (Edholm et al., 2010), and in rainbow trout (Ramirez-Gomez et al., 2012), but with some differences because it did not contain $\mathrm{V}$ domain in the former, while it did in rainbow trout. Of note, IgD has been found in most vertebrates, and it has orthologs even in Chondrichthyans (known as IgW), suggesting that it represents a primordial Ig class, like IgM (Ohta and Flajnik, 2006). To date, IgD seems to be missing only in birds, and in few mammalian species. No IgD sequence was found in the chicken $\operatorname{IgH}$ locus (Zhao et al., 2000 ) and seems to be absent from the chicken genome. $\operatorname{IgD}$ could not be found from available sequences from duck and ostrich either (Lundqvist et al., 2001; Huang et al., 2012). In the same line, $\operatorname{IgD}$ is apparently absent from the elephant and opossum IgH loci (Wang et al., 2009; Guo et al., 2011).

IgT/IgZ was discovered in Hansen et al. (2005) in rainbow trout (IgT) and zebrafish (IgZ; Danilova et al., 2005). It does not exist in other vertebrates but fish. IgH $\tau / \zeta$ may contain different numbers of $\mathrm{C}$ domains: four $\mathrm{C}$ domains are found in most species (Salinas et al., 2011), whereas stickleback (G. aculeatus) has three and fugu (Takifugu rubripes) has two. In carp (C. carpio) IgT is a chimeric protein containing a $\mathrm{C} \mu 1$ domain and a $\mathrm{C} \tau / \zeta$ domain (Savan et al., 2005). No Ig $\tau / \zeta$ locus could be found in the Medaka genome or in the Channel catfish, but it might be identified in catfish when the full genome sequence will be available. Recent studies performed in trout demonstrate that IgT is especially critical for the protection of mucosal territories in this species (Zhang et al., 2010), as suggested by the fact that the local ratio of $\operatorname{IgT}$ to $\operatorname{IgM}$ is $>60$-fold higher in the gut mucus than in serum. Furthermore, fish surviving an infection by the gut parasite Ceratomyxa shasta had elevated titers of parasite-specific IgT only in the gut mucus but not in the serum, while high titers of parasite-specific IgM were measured in the serum but generally not in the mucus. Additionally, as for IgA in human, an important property of IgT in the gut of rainbow trout seems to be its ability to recognize and coat a large percentage of luminal bacteria at steady state. Secreted IgT is found in trout serum as a monomer, and in mucus as a tetramer (Zhang et al., 2010).

Remarkably, neither IgG nor IgE are present in fish, even though long-lasting protection against secondary infection exists, and many parasites can infect fish.

\section{Fish IgH loci: structure and number across fish species}

The archetypal structure of the IgH loci follows a pattern of translocon organization with a region containing $\mathrm{VH}$ genes in $5^{\prime}$, followed by units comprising several $\mathrm{D}, \mathrm{J}$, and then $\mathrm{C}$ region genes in $3^{\prime}$. The $\mathrm{D} \tau-\mathrm{J} \tau-\mathrm{C} \tau$ cluster(s) encoding IgT specific genes are generally located between the region containing the $\mathrm{VH}$ genes and the $\mathrm{D} \mu / \delta-\mathrm{J} \mu / \delta-\mathrm{C} \mu-\mathrm{C} \delta$ locus. This structure is found for example in the zebrafish, grass carp, and fugu (Figure 2A). In this case, the configuration of $\mathrm{IgH}$ loci imposes the alternative production of either IgT or IgM/D rearrangements at a given locus since the recombination of $\mathrm{VH}$ to $\mathrm{D} \mu$ deletes the $\mathrm{D} \tau-\mathrm{J} \tau$ $\mathrm{C} \tau$ region(s). Since most $\mathrm{VH}$ genes are located upstream of both $\mathrm{DH} \tau$ and $\mathrm{D} \mu / \delta$, they can probably be used by $\operatorname{IgT}$, IgM, and $\operatorname{IgD}$ 


\section{A Zebrafish \\ Grasscarp \\ Fugu \\ Chr. 3; $175 \mathrm{~Kb}$ \\ Chr. ?; $137 \mathrm{~Kb}$ \\ Chr. $5 ; 130 \mathrm{~Kb}$ \\ $\mathrm{V}_{(38)} \quad \mathrm{D} / \mathrm{J} \quad \mathrm{C} \xi_{4)} \quad \mathrm{D} / \mathrm{J} \quad \mathrm{C \mu}_{(4)} \mathrm{C} \delta_{(16)}$

B

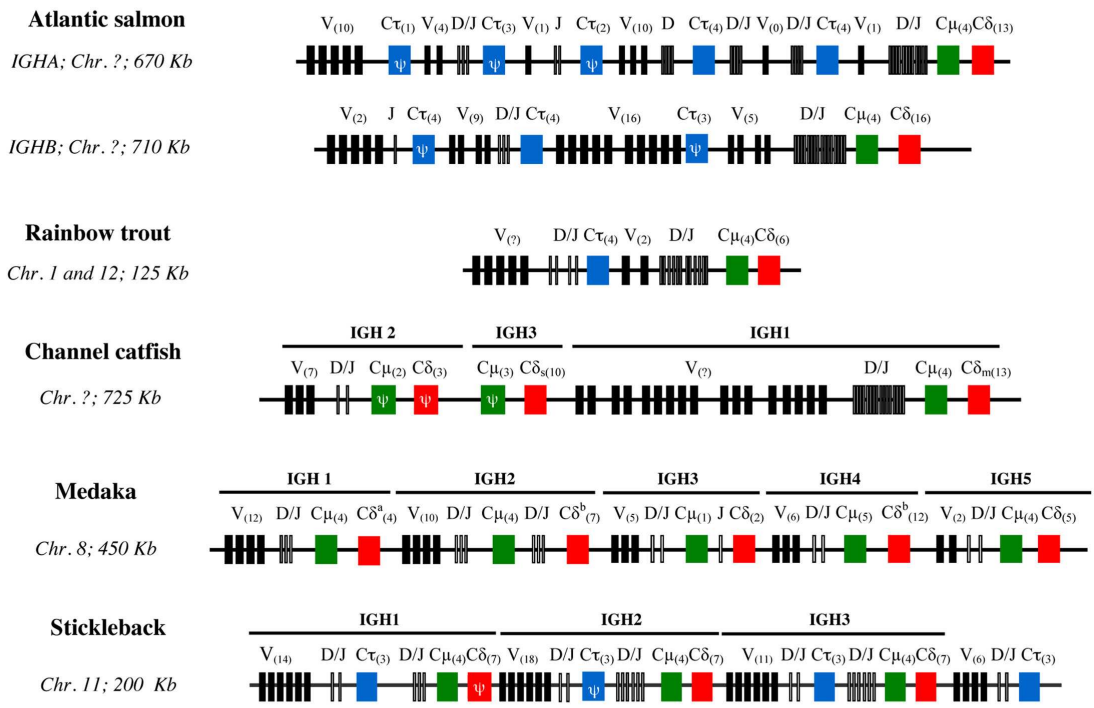

C

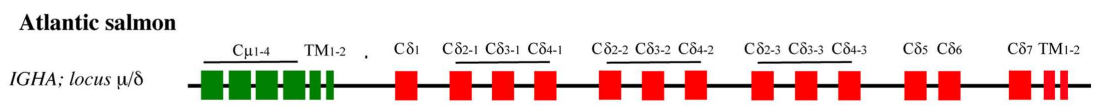

FIGURE 2 | Schematic structure of IgH loci in different teleost species. (A) IgH loci with archetypic structure in zebrafish, grass carp, and fugu. (B) Variants of IgH structure found in other species with partial or complete duplications present in different chromosomes (Chr.) (Atlantic salmon, rainbow trout) or in the same chromosome (channel catfish, three-spined stickleback, and Japanese medaka) (Chr.). The schemes are not in scale and depict the genomic configuration of $\mathrm{V}$ sets (black boxes), D and $\mathrm{J}$ sets (narrow gray boxes), and $\mathrm{CH}$ gene sets. $\mathrm{C} \mu$ are represented as green boxes, $\mathrm{C} \delta$ as red boxes, and $\mathrm{C} \tau / \zeta$ as blue boxes. The number of in frame $\mathrm{V}$ genes and $\mathrm{CH}$ exons are indicated in brackets within boxes. $\mathrm{CH}$ sequences with frameshift mutations are considered as pseudogenes $(\Psi)$. Catfish $\operatorname{lgH}: \mathrm{C} \delta_{\mathrm{s}}$ and $\mathrm{C} \delta_{\mathrm{m}}$ correspond to the secreted and membrane $\operatorname{lgD}$ coding genes, respectively. Medaka IgH: in the $\mathrm{C} \delta^{\mathrm{a}}$, the genomic sequence presents a gap and the actual number of $\mathrm{C} \delta$ domains is unknown; $\mathrm{C} \delta^{\mathrm{b}}$ indicates the presence of $\mathrm{C} \mu$ domains inserted between $\mathrm{C} \delta$ exons. The "?" symbol indicates a lack of data. (C) Detailed exon structure of the IgHA $\mu-\delta$ region in Atlantic salmon.
(Danilova et al., 2005; Hansen et al., 2005). A large number of VH genes are either pseudogenes, or their sequence is not complete in the genome assembly. Therefore, the diversity of functional $\mathrm{VH}$ genes is difficult to estimate. Beyond these general features, the structure of the loci coding for the isotypes corresponding to $\operatorname{IgM}, \operatorname{IgD}$, and $\operatorname{IgT}$ is surprisingly diverse among teleost fish species, due to successive episodes of genome duplications and gene loss.

Various number of IgH loci can be found in teleost species. The number of IgH loci varies among teleosts, and in some cases isoloci can even be found on different chromosomes (Figure 2B).

Salmonids such as Atlantic Salmon and rainbow trout possess two IgH isoloci (IgHA and IgHB) due to the tetraploidization of Salmonidae (Yasuike et al., 2010). The two corresponding IgM subtypes seem to be expressed at the mRNA level in Atlantic salmon and brown trout, but only one is found in rainbow trout and arctic char, suggesting that one of the two isoloci may be non-functional in these last two species. In Atlantic salmon, considering both IgHA and $\mathrm{IgHB}$ isoloci, there are eight $\mathrm{C} \tau$ loci with variable numbers of $\mathrm{D} \tau$ and $\mathrm{J} \tau$ genes likely due to tandem duplications, but only three out of these eight loci seem to be functional (two for IgHA and one for IgHB). In contrast, there is only one $\mathrm{D} \mu / \delta-\mathrm{J} \mu / \delta-\mathrm{C} \mu-\mathrm{C} \delta$ region per isolocus.

Cyprinids can also have different types of IgH loci. Zebrafish has only one IgH locus with the archetypic structure, as mentioned above (Danilova et al., 2005). The common carp has two subclasses of IgT/Z: IgZ1 is similar to the zebrafish IgZ while the IgZ2 contains a C $\mu 1$ domain (Ryo et al., 2010). It seems that the two carp IgZ are expressed from two distinct loci, but it is not clear at present whether these loci are located on the same chromosome. The common carp genome has been recently sequenced, and may provide novel information when fully annotated (Henkel et al., 2012). 
In other species like channel catfish, medaka, and three-spined stickleback, tandem duplications of the IgH locus have been found (Figure 2B). The channel catfish IgH region contains three $\mu / \delta$ loci, yet only $1 \mu$ is functional and $\tau / \zeta$ has not been found so far. The absence of IgT, which still has to be confirmed by full genome sequencing, might be due to a gene loss in the early evolution of Ictalurids. Intriguingly, in catfish the membrane IgD and the (V-less) secreted IgD are always produced from the two different functional C $\delta$ (Bengtén et al., 2006). It remains to be determined whether they could be expressed from the same haplotype. In the medaka genome, five regions encoding constant domains of IgM and IgD have been identified in one large locus (MagadánMompó et al., 2011). The analysis of Expressed Sequence Tags (ESTs) suggests that the IGH3 region is disorganized and might be non-functional (Figure 2B). No IgT gene has been found so far in this species. In the stickleback genome, three sets of $\tau / \zeta-\mu-\delta$ loci separated by $\mathrm{VH}$-containing regions have been described, evoking recombination units as found in mouse $\lambda$ light chains or shark IgH loci (Bao et al., 2010; Gambón-Deza et al., 2010).

The structure of the IgH locus differs between fish species. A precise examination of fish IgH shows that the structure of IGH $\delta$ is remarkably heterogeneous among fish species with frequent $\mathrm{C}$-domain duplications, while $\operatorname{IgH} \mu$ and likely $\operatorname{IgH} \tau$ appear to be more conserved. For example, $\mathrm{C} \delta 2-\mathrm{C} \delta 3-\mathrm{C} \delta 4$ domains are repeated three times in Atlantic salmon IgHA (Figure 2C) and catfish, and four times in zebrafish and Atlantic salmon IgHB. In puffer fish, the IgD gene comprises a longer tandem $\mathrm{C} \delta 1 \rightarrow \mathrm{C} \delta 6$ duplication (Saha et al., 2004). The rainbow trout $\mathrm{IgD}$ gene is also particular as it carries a $\mathrm{C} \delta 1-\mathrm{C} \delta 2 \mathrm{a}-\mathrm{C} \delta 3 \mathrm{a}-\mathrm{C} \delta 4 \mathrm{a}-\mathrm{C} \delta 2 \mathrm{~b}-\mathrm{C} \delta 7$ configuration, which seems to be the result of a first duplication of C $82-\mathrm{C} \delta 4$ present in $\mathrm{C} \delta 1-\mathrm{C} \delta 2-\mathrm{C} \delta 3-\mathrm{C} 84-\mathrm{C} \delta 5-\mathrm{C} \delta 6-\mathrm{C} \delta 7$, leading to $\mathrm{C} \delta 1-\mathrm{C} \delta 2 \mathrm{a}-\mathrm{C} \delta 3 \mathrm{a}-\mathrm{C} \delta 4 \mathrm{a}-\mathrm{C} \delta 2 \mathrm{~b}-\mathrm{C} \delta 3 \mathrm{~b}-\mathrm{C} \delta 4 \mathrm{~b}-\mathrm{C} \delta 5-\mathrm{C} \delta 6-\mathrm{C} \delta 7$, followed by deletion of the $\mathrm{C} \delta 3 \mathrm{~b}-\mathrm{C} \delta 6$ domains (Hansen et al., 2005). In the Japanese flounder and stickleback there is no $\mathrm{C} \delta$ domain duplication (Hirono et al., 2003; Hansen et al., 2005; Bao et al., 2010; Gambón-Deza et al., 2010). Of note, fish IgM and IgD are co-produced through alternative splicing of a long pre-mRNA containing the VDJ region, the $\mathrm{C} \mu$ exons, and the $\mathrm{C} \delta$ exons, as in mammals (Figure 3A). Precisely, fish IgH $\delta$ mature transcripts are produced by splicing of the donor site at the end of the $\mathrm{C} \mu 1$ exon to the acceptor site of the first C $\delta$ exon (Wilson et al., 1997), which results in a chimeric $\mathrm{C} \mu 1 / \mathrm{C} \delta$ molecules.

\section{Different Ig splicing patterns are used by distinct fish species to generate membrane IgM}

In mice and humans, membrane, and secreted $\operatorname{IgM} \mathrm{H}$ chains are produced from the same pre-mRNA through alternative splicing. A membrane Ig $\mu$ transcript is made if a cryptic splice site located within $\mathrm{C} \mu 4$ is spliced to the acceptor site of the transmembrane (TM) 1 exon, and a secreted Ig $\mu$ transcript is produced when the mRNA is polyadenylated between the last constant $(\mathrm{C})$ region domain $\mathrm{C} \mu 4$ and the TM exons. In fish, membrane Ig $\mu$ transcripts have the TM exons spliced to the donor site located at the $3^{\prime}$ end of the $\mathrm{C} \mu 3$ exon, hence they lack the last $\mathrm{C} \mu$ domain $(\mathrm{C} \mu 4)$ that is present in the secreted Ig $\mu$ transcripts (Figure 3B;

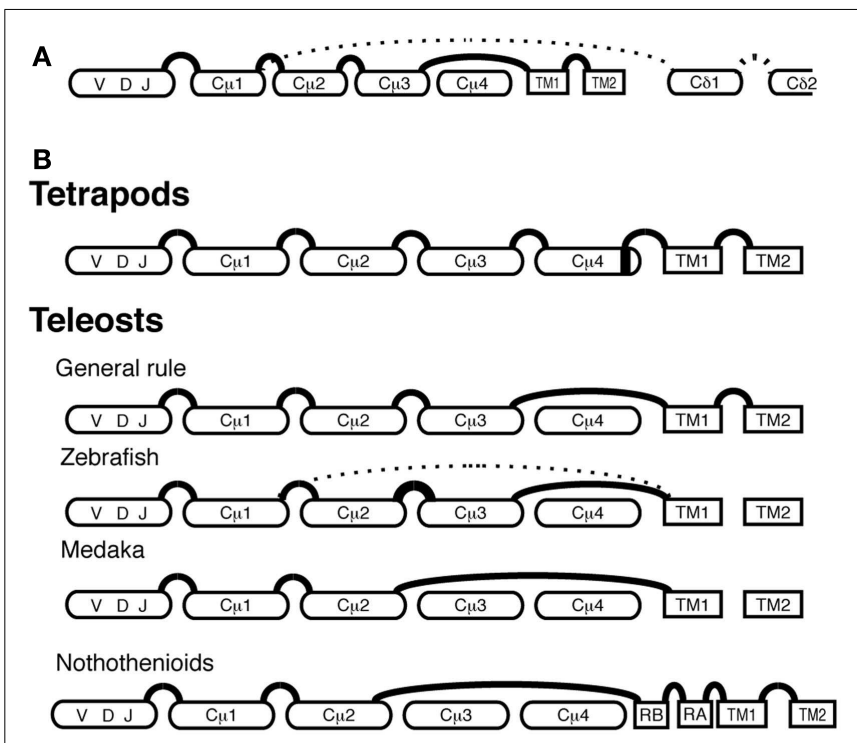

Ancient «fishes": the example of siberian sturgeon

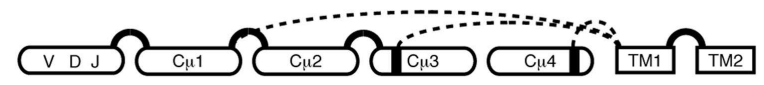

FIGURE 3 | Representation of IgH splicing alternative pathways in fish and tetrapods. The alternative splicing leading to $\lg H \mu$ (plain line) and to $\lg \mathrm{H} \delta$ (dotted line) mature mRNAs (A). IgH $\mu$ RNA splicing pathways in different fish groups and in Tetrapods (B): plain and dotted lines represent general and alternative splicing pathways, respectively.

Bengtén et al., 1991; Lee et al., 1993; van Ginkel et al., 1994). Exceptions to this rule have been found in different species. The medaka membrane Ig $\mu$ lacks both $\mathrm{C} \mu 3$ and $\mathrm{C} \mu 4$ domains because the $\mathrm{TM}$ exons are spliced directly to the $3^{\prime}$ end of the $\mathrm{C} \mu 2$ domain (Magadán-Mompó et al., 2011). In the Antarctic Notothenioids fish, membrane Ig $\mu$ transcripts also lack these domains (Coscia et al., 2010) but two exons consisting of 39-nt (RA and RB) are present between the C $\mu 2$ and TM1 exons (Coscia et al., 2010). This splicing pattern, which is found in most of the Antarctic Notothenioids, may represent an adaptive selection of IgM during Notothenioid evolution (Coscia and Oreste, 2003). In the zebrafish, in addition to the classical VDJ-C $\mu 1-C \mu 2-C \mu 3-T M 1-$ TM2 mRNA, an alternative VDJ-C $\mu 1-T M 1-T M 2$ membrane Ig $\mu$ transcript has been reported, which encodes only one $\mathrm{CH}$ domain (Hu et al., 2011). This implies that B cells can express two different forms of membrane IgM in this species, which increases the number of expressed Ig isotypes. Noteworthy, the functional implication of these various splicing patterns for B cell functions is unknown.

In ancient lineages of fish such as holosteans, the bowfin (Amia calva), and the long-nose gar (Lepisosteus osseus) a remarkable diversity of splicing patterns of the membrane Ig $\mu$ transcripts was also observed (Wilson et al., 1995a,b). In chondrosteans, another ancient fish lineage, the diversity of membrane Ig $\mu$ transcripts is even higher: in Siberian sturgeon (Acipenser baerii) the TM1 exon is alternatively spliced to three possible donor sites: a cryptic site at the end of $\mathrm{C} \mu 4$, a cryptic site at the end of $\mathrm{C} \mu 3$, and the 
donor splice site at the $3^{\prime}$ end of $\mathrm{C} \mu 1$, leading to IgM H chains with four, two, or only one complete $\mathrm{C} \mu$ domain(s) (Lundqvist et al., 2009; Figure 3B). The shortest membrane Ig $\mu$ splice variant might have specialized functions because it was retrieved only in transcripts expressing VH2 (Lundqvist et al., 2009). This diversification of splicing pathways to produce membrane IgM in the "ancient fish" lineages evokes a highly diverse situation after whole-genome duplication in the early fish evolution, followed by standardization to the $\mathrm{C} \mu 3 \rightarrow$ TM1 splicing pattern in teleosts before their great radiation. However, the particular situations found in ice fish (Notothenioids) or even in zebrafish or medaka indicate that this standardization is not universal.

\section{IgL loci in teleost fish}

Four immunoglobulin light chain ( $\operatorname{IgL}$ ) isotypes have been described in teleosts: L1, L2, L3, and $\lambda$ (Edholm et al., 2009; Bao et al., 2010). A recent comprehensive phylogenetic analysis of vertebrate VL and CL sequences suggested that fish L1 and L3 chains are $\kappa$ orthologous (Criscitiello and Flajnik, 2007), and fish L2 are orthologs of Xenopus $\sigma$ (Partula et al., 1996). The current general classification of IgL from all vertebrates distinguishes four clans based on phylogenetic relationships: $\kappa$ (mammalian $\kappa$, elasmobranch Type III, Teleost L1, and L3, Xenopus $\rho$ ), $\lambda$ (mammalian $\lambda$, elasmobranch type II), $\sigma$ (Xenopus $\sigma$, teleost L2, elasmobranch type IV), and $\sigma$ cart ( $\sigma$-cart, that is restricted to elasmobranch).

Light chain genes in fish genomes are found as multiple VLJL-CL units. The genomic organization of VL-JL-CL unit is conserved in teleosts. For the $\mathrm{L} 1$ and $\mathrm{L} 3$ loci, the $\mathrm{V}$ genes are in opposite transcriptional orientation with respect to the $\mathrm{J}$ and $\mathrm{C}$ segments. In contrast, in L2 and $\lambda$ clusters $\mathrm{V}$, J, and C genes are in same orientation (Daggfeldt et al., 1993; Ghaffari and Lobb, 1993, 1997; Timmusk et al., 2000), with the exception of stickleback L2 (Bao et al., 2010). In a genome wide study in zebrafish, such clusters have been found in five different chromosomes (Zimmerman et al., 2008). Interestingly, VL-JL rearrangements between distinct units were reported in this species, which might be a means of increasing the potential combinatorial diversity.

It is intriguing that to date no pseudo light chain corresponding to eutherian mammal VpreB or $\lambda 5$ has been reported in fish. In mammals, these chains play a crucial role in the stepwise process of Ig chains rearrangements that take place during B cell development. A deficiency in VpreB or $\lambda 5$ results in a block of B cell development at the pre-B cell stage in mice (Kitamura et al., 1992). In fish, it is still unknown if an alternative pre-B cell receptor that lacks the $\mathrm{VpreB} / \lambda 5$ surrogate light chain forms during $B$ cell development. In fact, it is not known if Ig gene rearrangements in fish follow the ordered model described in mouse and human; moreover, no pre-T $\alpha$ receptor has been found in fish, while it was recently discovered in sauropsids (Smelty et al., 2010). Similarly, the mechanisms ensuring allelic exclusion in fish are unknown.

\section{PATHWAYS AND ENZYMATIC MACHINERY OF Ig REARRANGEMENT AND DIVERSIFICATION \\ The enzymatic machinery of Ig gene rearrangement: similarities between fish and mammals}

The rearrangement of VDJ genes is mediated in mammals by a complex enzymatic machinery that includes recombination activating genes (RAG)-1 and 2, proteins from the nonhomologous end joining (NHEJ) pathway of repair of DNA double strand breaks, and DNA polymerases of the $\mathrm{X}$ family polymerase $\lambda$, polymerase $\mu$, and terminal deoxynucleotidyl transferase (TdT). RAG are lymphocyte-specific enzymes that mediate the first steps of VDJ recombination including recognition of the Recognition Sequence Signal (RSS) situated on the sides of the Ig gene segments recruited in the rearrangement, cleavage of DNA at these RSS sites, and hairpin formation as well as resolution. The NHEJ components (Ku70, Ku80, DNAPK, XRCC4, ligase IV, and ARTEMIS) constitute the major pathway involved in the repair of the double strand DNA breaks introduced by the RAG enzymes. The resolution of the DNA breaks is preceded by the action of polymerases $\lambda$ and $\mu$, which mediate DNA deletional trimming at the junction site, and TdT, which adds " $\mathrm{N}$ " nucleotides in a template-independent manner in VDJ junctions. The enzymes implicated in the molecular machinery of Ig rearrangements are remarkably conserved between mammals and fish (Table 2).

RAG1 and RAG2 from fish were first cloned in rainbow trout (Hansen and Kaattari, 1996; Hansen, 1997) and zebrafish (Greenhalgh and Steiner, 1995; Willett et al., 1997). They are expressed in tissues where rearrangement activity is expected, and a zebrafish with a truncated RAG1, identified by screening of $N$-ethyl- $N$-nitrosourea mutants, is unable to make VDJ rearrangements, indicating that this enzyme is required for this process in zebrafish as in mammals (Wienholds et al., 2002). In line with this, $\mathrm{V}, \mathrm{D}$, and $\mathrm{J}$ segments of fish $\operatorname{IgH}$ and $\operatorname{IgL}$ are flanked by typical RSS (Ghaffari and Lobb, 1997; Hayman and Lobb, 2000). Of note, RSS-like heptamers and nonamers were found within some JL-CL introns (Ghaffari and Lobb, 1997) as well as in 3' region of the majority of the zebrafish CL genes (Zimmerman et al., 2011), evoking the isolated RSS heptamer recombination element located in mouse J $\kappa-\mathrm{C} \kappa$ intron, which can recombine with the $\kappa$-deleting element located downstream of Ск exon to delete the Ск exon and silence the Igк locus (Vela et al., 2008). Such process of locus inactivation might provide a mechanism to achieve allelic exclusion for fish IgL (Vela et al., 2008).

The genes coding for the main enzymes of the NHEJ machinery appear to be present in fish genomes, with (recent) duplications for some of them in zebrafish (Table 2). An ortholog of Ku70 was identified in zebrafish that was critical for protection from radiation-induced DNA damage because embryos in which this gene was knocked-down were highly sensitive to ionizing radiation (Bladen et al., 2007).

Orthologs of the X family of DNA polymerases involved in diversification of VDJ junctions have also been identified in fish. The gene coding for TdT was found in rainbow trout and zebrafish genomes (Hansen, 1997; Beetz et al., 2007). It is expressed in lymphoid tissues where rearrangements occur (thymus, pronephros, mesonephros, spleen, and gut). Both TCR and Ig junctions contain $\mathrm{N}$ diversity, suggesting that fish TdT has similar functions as in mammals. In zebrafish polymerase $\mu$ is expressed also in primary lymphoid tissues, as well as in ovary and testis (Beetz et al., 2007). Thus, the mechanisms of Ig rearrangement might be similar in teleosts and mammals. 
Table 2 | Genes of the key participants of the rearrangement machinery in fish.

\begin{tabular}{|c|c|c|c|}
\hline & Reference & Zebrafish & Stickleback \\
\hline Rag 1 & $\begin{array}{l}\text { Hansen and Kaattari (1995), Hansen and Kaattari (1996), } \\
\text { Greenhalgh and Steiner (1995), Willett et al. (1997) }\end{array}$ & ENSDARG00000052122 & ENSGACG00000011465 \\
\hline Rag2 & & ENSDAzRG00000052121 & ENSGACG00000011461 \\
\hline \multicolumn{4}{|l|}{ NHEJ } \\
\hline \multirow[t]{2}{*}{ Ku>0 } & Bladen et al. (2007) & ENSDARG00000090718 & ENSGACG00000004868 \\
\hline & & ENSDARG00000071551 & \\
\hline \multirow[t]{2}{*}{ Ku80 } & & ENSDARG00000068862 & ENSGACG00000006130 \\
\hline & & ENSDARG00000015599 & \\
\hline$X R C C 4$ & & ENSDARG00000010732 & ? (But present in a number of other fish) \\
\hline$D N A P K$ & & ENSDARG00000075083 & ENSGACG00000001974 \\
\hline Artemis/DCLRE1C & & ENSDARG00000045704 & ENSGACG00000020073 \\
\hline Ligase IV & & ENSDARG00000060620 & ENSGACG00000014135 \\
\hline \multicolumn{4}{|l|}{ POLYMERASES $X$} \\
\hline Polymerases $\lambda$ & & ENSDARG00000039613 & ENSGACG00000018272 \\
\hline Polymerases $\mu$ & Beetz et al. (2007) & ENSDARG00000042507 & ENSGACG00000001887 \\
\hline$T d T$ & Hansen (1997), Beetz et al. (2007) & ENSDARG00000038540 & ENSGACG00000002880 \\
\hline
\end{tabular}

It is interesting to note that the genes coding for some of these enzymes are present in the genomes of ancient fish such as cartilaginous elasmobranch (which include shark, ray, and skates). TdT from elasmobranch has structural similarities with the mouse $\mathrm{TdT}$, in agreement with the fact that both enzymes have templateindependent mode of DNA elongation without strong nucleotide bias (Bartl et al., 2003). These data suggest that TdT and other polymerases from the ancient family of polymerases $\mathrm{X}$ were used by the rearrangement machinery even before the divergence of fish and mammals (Beetz et al., 2007).

\section{Mechanisms of hypermutation: presence and limits}

The affinity maturation of antibody responses is less efficient in cold blood vertebrates compared to mammals (Wilson et al., 1992). For example after immunization of rainbow trout with the hapten-carrier antigen TNP-KLH (trinitrophenyl-linked to keyhole limpet hemocyanin), the affinity of the antigen-specific antibody response progressively increased over 27 weeks, with initial production of low affinity antibodies, which were replaced within 5 weeks by antibodies of intermediate affinity, and after 15 weeks by antibodies that had the highest affinity for antigen (Ye et al., 2011). It is assumed that the low efficiency of the affinity maturation of the antigen-specific antibody response in fish is due to the absence of typical germinal centers (GC), which are the specialized anatomical structures supporting the selection of B cells expressing high affinity B cell receptor (BCR) for antigen in mammals (Wilson et al., 1992). However, clusters of cells containing melano-macrophages were found in spleen and kidney of channel catfish, which might represent primordial GC because activation-induced deaminase (AID) was expressed in these structures (Saunders et al., 2010). AID is a critical enzyme for somatic hypermutation and class switch recombination of Ig genes in mammals. Fish AID differ from their mammalian counterparts at the level of the catalytic sites, but puffer fish and zebrafish AID could nonetheless mediate Ig class switch recombination in mouse B cells (Barreto et al., 2005). In catfish hypermutated IgH sites show an accumulation of $\mathrm{G} \rightarrow \mathrm{A}$ and $\mathrm{C} \rightarrow \mathrm{T}$ substitutions consistent with AID activity. However, the pattern of Ig somatic hypermutation has particular characteristics in fish, with sequence motifs containing hypermutation hotspots different from those known in mammals (Yang et al., 2006). Interestingly, there was no difference in the ratio of replacement-to-silent mutations in the complementarity determining regions (CDR), which correspond to the Ig parts involved in antigen binding, and in the framework regions, which are normally not involved in antigen binding. Thus, the mechanism of Ig somatic mutation did not coevolve in fish with the pathways mediating selection of B cells with non-synonymous substitutions specifically within CDR-encoded regions. Fish Ig structure suggests that as in mammals CDR are most important for antigen binding, and that they form the main part of the antigen binding surface. A possible explanation for this finding is that mutated Ig sequences do not undergo positive selection for affinity maturation efficiently due to the lack of an appropriate micro-environment. In this context, the primary role of the process of somatic hypermutation might have been to diversify the available repertoire by targeting hotspot motifs preferentially located within CDR-encoded regions. Whether part of this diversity might have deleterious specificity and require particular negative selection remains unknown. In zebrafish, a comprehensive analysis of $\operatorname{IgH} \mu$ transcripts via deep sequencing indicated that the frequency of Ig sequences with high numbers of somatic mutations increased with age (up through 1 year), in agreement with the notion that hypermutation brings a significant contribution to the diversification of the Ig repertoire (Jiang et al., 2011). Fish Ig light chains can also be subjected to hypermutation (Marianes and Zimmerman, 2011), as previously observed in shark (Lee et al., 2002). It is so far unknown whether fish AID, like mammalian ones, can specifically target additional genes with frequent translocations in tumors, repetitive sequences, and histone H3K4 trimethylation (Kato et al., 2011). The gene aid is found 
in the genome of the main fish model species within conserved synteny groups, indicating they represent true orthologs of the mammalian gene (see zebrafish ENSDARG00000015734, stickleback ENSGACG00000010521, fugu ENSTRUG00000007079 in the Ensembl website).

\section{THE CENTRAL B CELL SYSTEM IN FISH}

Three modes of early hematopoiesis have been described in fish (Zapata et al., 2006): hematopoiesis can start in the yolk sac blood islands like in the angelfish, or in intraembryonic intermediate cell mass (ICM) as in zebrafish; alternatively it may initiate for a short time in the yolk sac before continuing in the ICM as in rainbow trout. In zebrafish, the hematopoietic activity appears at 4 days post-fertilization (dpf), but gives rise first to erythroblasts and myeloid cells. Fish B cell lymphopoiesis appears and occurs mainly in the kidney. The expression of zebrafish RAG2 was observed at $8 \mathrm{dpf}$ in the pronephros of Rag2-Gfp transgenic fish, which was the earliest extrathymic site of RAG expression (Trede et al., 2004). AID mRNA was even detected at $2 \mathrm{dpf}$ in this species by analysis of gene expression on the whole embryo (Trede et al., 2004). The first VHDHJH rearrangements were detected around $4 \mathrm{dpf}$ (Danilova and Steiner, 2002), but cells expressing IgM (Lam et al., 2004) appeared in the kidney only at 3 weeks post-fertilization, suggesting a slow process of $B$ cell maturation. In the rainbow trout, RAG expression occurred earlier, from $10 \mathrm{dpf}$ onward, and membrane IgM-expressing cells became detectable at hatching (Razquin et al., 1990), around $3 \mathrm{wpf}$ (Hansen, 1997). The spleen seems to have much less importance for B cell lymphopoiesis than the kidney tissue, if any.

In adult fish, B cells reside in the anterior and posterior kidney, spleen, gut lamina propria, and blood (Rombout et al., 1993; Abelli et al., 1997). Several B cell subsets can be distinguished according to their expression of distinct Ig class combinations. In some fish species two subsets of B cells can be identified by their expression of both IgM and D, or IgT only. The development of $\operatorname{IgM}^{+} \operatorname{IgD}^{+}$ $\mathrm{B}$ cells and $\mathrm{IgT}^{+} \mathrm{B}$ cells involves two different pathways because in zebrafish with a deficiency in Ikaros gene $\operatorname{IgT}^{+} \mathrm{B}$ cells are totally lacking, while $\operatorname{IgM}^{+}$B cells are present, even though their appearance shows a delayed kinetic (Schorpp et al., 2006). Moreover, these two types of B cells are differently localized in the organism. $\mathrm{IgM}^{+} \mathrm{B}$ cells are the main B cell population (75-80\%) in spleen, kidney, and blood, while $\operatorname{IgT}^{+} \mathrm{B}$ cells represent the main $\mathrm{B}$ cell subset (55\%) in gut-associated lymphoid tissues (Zhang et al., 2010). The existence and importance of $\operatorname{IgM}^{-} \operatorname{IgD}^{+} \mathrm{IgT}^{-} \mathrm{B}$ cells in fish is a matter of debate. While in most fish species it is considered that $\operatorname{IgD}$ is always co-expressed with $\operatorname{IgM}$, a distinct population of $\mathrm{IgM}^{-} \mathrm{IgD}^{+} \mathrm{B}$ cells has recently been identified in the channel catfish, which preferentially expresses $\sigma$ IgL (Edholm et al., 2010). The frequency of this population is highly variable between individuals, ranging from a few percent to more than $70 \%$ of B cells within peripheral blood leukocytes. The participation of these cells to immune responses is not known.

Fish B cells show different homing patterns depending on their development and activation stages. B cell progenitors and plasma cells are dominant in the anterior kidney, while mature B cells and plasma blasts are primarily found in posterior kidney (Zwollo et al., 2005; Zwollo, 2011). Spleen leukocytes also contain B cells that can differentiate into plasma cells. Based on these data, it can be envisioned that $\mathrm{B}$ cell development occurs in the anterior kidney, from where mature B cells enter the blood/lymph to reach the spleen and posterior kidney, where they can become activated and differentiate into plasma blasts and then plasma cells, which migrate back to the anterior kidney where they might subsist as long-lived cells in particular niches. Such model suggests that B cells use the same tissue for their development as plasma cells for their residence, as previously observed in mammals.

\section{The B cell repertoire in the healthy fish}

The modalities of $\mathrm{B}$ cell selection to produce a naïve repertoire remain unknown in fish. The development of highthroughput sequencing methods now makes possible a comprehensive description of expressed immune repertoires. The first exhaustive sequencing of a B cell expressed diversity in a vertebrate was performed in zebrafish by Weinstein et al. (2009) using 454 GS FLX pyrosequencing. In this study, whole-fish mRNA was prepared from 14 individuals belonging to 4 families, and the variable domain (VDJ region) of IgH $\mu$ sequenced. The expressed IgM repertoire was studied in quiescent state, from healthy fish that had been raised in classical aquarium environment and possessed a normal gut microbial flora. It was estimated that a large proportion of the possible $\mathrm{V} / \mathrm{J}$ combinations (50-86\%) were expressed. Interestingly, the distribution of VDJ diversity was similar between individuals, and identical $\mu$ heavy chains were found in distinct fish more often than expected. This study established that the expressed IgM repertoire of different fish belonging to distinct families shared some patterns, a property which was called stereotypy. The same laboratory also followed the evolution of the expressed IgM repertoire during zebrafish development (Jiang et al., 2011). In 2-weeks-old fish, the repertoire of VDJ combinations showed a high level of stereotypy, suggesting that the primary repertoire was strongly constrained. In such young fish, which have few (if any) antibody-secreting cells, the abundance, and the junctional sequence diversity of VDJ combinations correlated. In contrast, this correlation was lost in 3-month-old fish. This was likely due to the higher frequency of antibody-secreting cells in these older animals. Nevertheless, the frequencies of VDJ combinations correlated between individuals, substantiating further the notion that deterministic forces regulate the structure of the primary repertoire. The apparent contradiction between a deterministic view of the expression of VDJ combinations and the loss of correlation between VDJ frequency and diversity in adult fish may be explained by the accumulation of different numbers of plasma cells in distinct adult fish.

In a different study, a combination of CDR3 length spectratyping and pyrosequencing was used to describe the expressed IgM, IgD, and IgT repertoires in rainbow trout (Castro et al., 2013). The VDJ domains expression was studied in the spleen of naïve individuals. Clonal isogenic animals were analyzed to avoid fishto-fish variation due to genetic heterogeneity. As in zebrafish, it was found that not all V/J combinations were expressed. In fact, only 7 out of $13 \mathrm{VH}$ families were retrieved. CDR3 length spectratyping and pyrosequencing showed that spleen Ig repertoires were very diverse for all three isotypes in healthy fish. IgM and IgD repertoires were rather similar for most $\mathrm{VH}$, while being significantly 
different from the IgT repertoire. This observation suggested that IgM and IgD repertoires were not subjected to drastic differential selection. The strong difference between IgT and $\operatorname{IgM} / \operatorname{IgD}$ CDR3 length profiles was consistent with the usage of a different set of rearrangements with specific $\mathrm{D}$ and $\mathrm{J}$ segments in $\mathrm{B}$ cells expressing either IgM/IgD or IgT. A more detailed analysis focused on the VDJ junctions. To compare the distributions of junctional sequences between individuals, sequence reads encoding a CDR3 region were annotated using IMGT/highV-QUEST for $\mathrm{VH}$, JH, and $\mathrm{C}$ genes, and aggregated into "junction sequence types" (JST). The abundance distribution of JST computed from pyrosequencing datasets indicated that $90-99 \%$ of junction sequences were found less than five times, likely corresponding to naive non-expanded B cells. Only few JST were found more than 20 times, possibly reflecting the presence of few antibody-secreting cells in the spleen of these fish, in good accordance with previous studies about spleen B cell subsets in rainbow trout (Bromage et al., 2004).

Taken together, these observations indicate that all VDJ combinations are not equally expressed, and suggest that, at least in zebrafish, the expressed repertoire exhibits a significant level of stereotypy.

\section{THE MODIFICATIONS OF FISH EXPRESSED Ab REPERTOIRES BY INFECTIONS AND VACCINES}

In fish, B cell responses occur against a variety of pathogens, and must occur in microenvironments different from those described in mammals, due to the lack of GC and lymph nodes. In this context, the clonal complexity of trout $\mathrm{B}$ cell responses is largely unknown. The development of high-throughput sequencing approaches of Ig transcripts combined with CDR3 length spectratyping can provide comprehensive analyses of $\mathrm{B}$ cell responses, which are required to understand the dynamics of their clonal complexity (Ademokun et al., 2011).

Such an approach was used to characterize the B cell response of rainbow trout against a rhabdovirus, the Viral Hemorrhagic Septicemia Virus (VHSV). Clonal fish were vaccinated using an attenuated virus, then challenged 3 weeks later with the same virus, and finally analyzed after three more weeks. At this stage, all fish had neutralizing antibodies against VHSV, and increased levels of total IgM as well as IgT in serum. The titer of IgM remained more than 10 times higher than of IgT after infection, and the ratio of $\operatorname{IgM}^{+} \operatorname{IgT}^{-} / \operatorname{IgM}^{-} \operatorname{IgT}^{+} \mathrm{B}$ cells was similar between infected and control fish. CDR3 length spectratyping showed that the VHSV infection triggered a strong IgM response. Indeed, $\mathrm{VHC} \mu$ spectratypes were extensively and significantly skewed in infected fish for all the analyzed $\mathrm{VH}$, as shown by a comparison of each peak in each spectratype profile using the ISEApeaks software (Collette and Six, 2002). Interestingly, the VH5.1-C $\mu$ profile showed a great amplification of the same peak in all infected individuals, suggesting a public response. In contrast, $\mathrm{VHC} \delta$ profiles showed only weak and sporadic alterations, which were not statistically validated. The low contribution of IgD to the response might reflect a down regulation of its expression in activated B cells, as in human and mice. This analysis also revealed a significant IgT response in spleen of infected fish. After VHSV infection, most splenic IgT spectratyping profiles were affected, although to a lesser extent compared to IgM. No peak expansion common to all infected fish was observed for IgT, suggesting the absence of a public response. Hence, the spleen might be a site of activation for $\mathrm{VHSV}$-specific $\operatorname{IgT}^{+} \mathrm{B}$ cells. This is intriguing because IgT is a specialized mucosal Ig.

The molecular diversity of IgM and IgT responses was further characterized by pyrosequencing of VHC junctions for different VH groups. Since a JST corresponds to a CDR3 protein sequence associated with a $(\mathrm{VH}, \mathrm{JH})$ pair, the distribution of the relative abundance of JST in different fish provides a description of the importance of antibody clonal responses. IgM JST distributions showed that the virus induced a major shift of the IgM expressed repertoire, with appearance of a significant number of highly represented JST (Figure 4).

Further analysis indicated that these large JST sets corresponded essentially to transcripts encoding secreted IgH, hence to antibody-secreting cells. When comparing the JST expanded in different infected fish, similar VH5.1-J5 rearrangements with CDR3 of 10 amino acids were present in all individuals. The CDR3 with the amino acid sequence ARYNNNAFDY was the most frequent, but a number of other related JST were found repeated in several individuals, with exchange of small or polar amino acids: ARYNNDAFDY, ARYDNNAFDY, ARYNSNAFDY, ARYNNVAFDY, ARYDDNAFDY, ARYNTNAFDY, ARYNGDAFDY, ARYSGDAFDY, and ARYNGRAFDY. Such expansion of a number

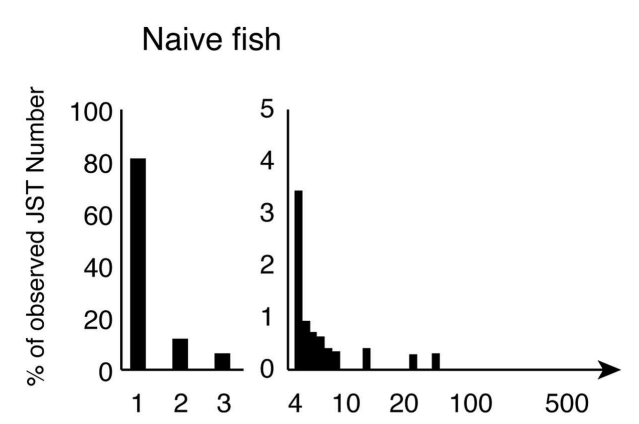

$\mathrm{Nb}$ of occurrence in the dataset
Infected fish

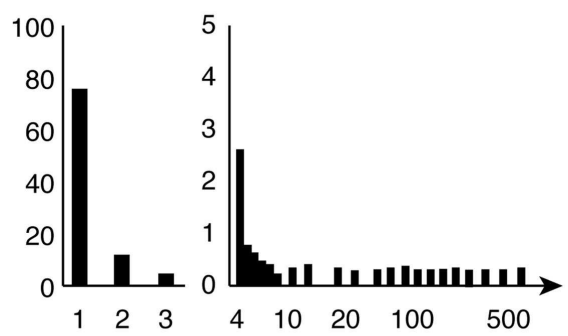

$\mathrm{Nb}$ of occurrence in the dataset

FIGURE 4 | Typical normalized distributions of JST in the pyrosequencing datasets. JST observed $n$ times from control and virus infected fish for a given $\mathrm{VH} / \mathrm{C}$ combination are represented as percentages of the total number of JST. Large clonal expansions are indicated by high number of occurrences of expressed JST in infected animals. 
of similar junctions found in several fish, and differing from the most frequent one by only one (or a few) conservative substitution(s) is typical of "public" responses in mammals (Bousso et al., 1998; Lin and Welsh, 1998). Importantly, this observation suggests that rainbow trout possess a common pool of pre-existing spleen $\mathrm{VH} 5.1^{+} \mathrm{B}$ cells among which the public IgM response to VHSV is recruited.

This pyrosequencing study also revealed the great importance and diversity of private clonal expansions in infected fish. It is at present unclear whether these expansions represent only VHSVspecific responses or include bystander-activated cells. It will be important to clarify this point, and whether bystander effects could be beneficial or detrimental to the host. In this regard, it is intriguing that fish injected with oil-adjuvanted vaccines developed an autoimmune syndrome with autoantibodies and liver lesions (Koppang et al., 2008).

\section{PERSPECTIVES}

The aim of this review was to provide a concise description of our current knowledge of fish Ig repertoire. It is clear that a lot of important unknowns remain in fish B cell biology. As perspectives, we have listed five topics below, which might provide interesting areas for future investigation.

\section{B CELL RECEPTOR ALLELIC EXCLUSION IN FISH}

Many aspects of Ig gene rearrangement and B cell biology remain mysterious in fish. In particular, the absence of the pseudo light chains VpreB and $\lambda 5$, which are required for the formation of pre-BCR in mammals, suggests that allelic exclusion is achieved by different mechanisms in fish and mammals. In fact, the regulation of VDJ recombination to ensure allelic and isotypic exclusion in fish is far from being understood. This question evokes the situation in sharks where the IgH locus organization consists of many (up to 200) independently rearranging miniloci: in these species, the rearrangement takes place within a minilocus, and only one or few $\mathrm{H}$ chain genes are fully rearranged in each $\mathrm{B}$ cell, whereas the other loci retain their germline configuration (Malecek et al., 2008). The mechanisms by which sharks and bony fishes regulate the progression of VDJ rearrangements might reveal pathways of general interest.

\section{MATURATION OF B CELL RESPONSE WITHOUT GC}

The process of hypermutation of Ig genes observed in fish in absence of typical GC is reminiscent of the affinity maturation that can occur in mammals in extra follicular foci in the spleen red pulp (Matsumoto et al., 1996). Its potential role in the diversification of the fish Ig repertoire also bears some similarities with the fact that at least a part of human marginal zone B cell pool expresses a $\mathrm{BCR}$ repertoire diversified through somatic hypermutation independently of GC, even though antigen stimulation via BCR does not seem to be involved in the latter case (Weill et al., 2009). Collectively, these examples highlight the diverse utilizations made during evolution of this remarkable process of somatic hypermutation of Ig genes, for the diversification of antibody repertoires. In fish, the existence of long-term protection and antigen-specific $B$ cell memory raises the question of differentiation of memory $B$ cells in absence of classical GC. In fact, memory B cells expressing high affinity, hypermutated IgG1 were found in lymphotoxinalpha deficient mice, which lack GC (Matsumoto et al., 1996). The alternative site of memory $\mathrm{B}$ cells differentiation has not been identified. The modalities of memory B cell formation outside GC represent both a practical issue for vaccination and a fundamental question in B cell biology.

\section{DIVERSITY OF B CELL REPERTOIRES}

The comprehensive description of fish $B$ cell repertoires and indepth statistical analyses have opened the way to comparative studies of the population dynamics of B cells in different fish species. The seminal work of Quake's group suggests that zebrafish antibody repertoires may harbor a higher level of stereotypy than expected. It will be interesting to understand if the total number of $B$ cells present at a given time has a strong influence on such patterns: a zebrafish may contain a few millions of B cells, while a trout has around 100-1000 times more, and a large tuna probably 100010,000 times more. It appears likely that the constraints exerted on $B$ cell diversity to express at once a complete repertoire able to cope properly with the diversity of relevant pathogens will be different in these species. Also, some fish species like Atlantic cod show very poor antibody responses (Espelid et al., 1991; Pilström and Petersson, 1991; Schrøder et al., 1992; Magnadottir et al., 2001), when having high level of serum antibodies and a repertoire strongly skewed toward the VHIII family (Stenvik et al., 2001), possibly reflecting a particular importance of natural antibodies. These particularities must be put in the context of the absence of CD4, LI, and MHC class II molecules (hence, lack of the equivalent of a $\mathrm{CD} 4{ }^{+} \mathrm{T}$ cell help activity) recently revealed by the analysis of the complete sequence of the cod genome (Star et al., 2011). As a group, teleost fish represent a rich diversity of species with a wide range of size and a complex history of whole-genome duplications. Future studies on B cell repertoires from different fish species will provide insightful information about the general rules of adaptation of this system, in fish and more generally in vertebrates.

\section{METHODOLOGIES FOR B CELL REPERTOIRE ANALYSIS}

CDR3 length spectratyping, also called Immunoscope, has been the standard technique for large-scale analysis of antigen receptors repertoire diversity for about 15 years (Pannetier et al., 1993, 1995). Systematic sequencing of "all” Ig transcripts expressed in a lymphocyte population of interest represents a step forward, and is made possible by the "next generation" sequencing technologies. A benefit of these approaches is clearly that several angles of analysis can be taken to focus on different aspects of the repertoire such as clonotypes frequency, Ig V-C or V-J CDR3 diversity, CDR3 sequence analysis, $\mathrm{V}$ allele identification, etc. The ability to process the complexity of the information provided in such amounts of data remains limited, and specific software developments for automatic annotation of Ig sequences, and statistical modeling of repertoire diversity can still be improved. New strategies will have to be developed, possibly from existing scoring systems. The most common is the Shannon entropy, introduced by Claude Shannon in 1948 for the information theory. Then, in 1961, Alfred Rényi has generalized the utilization of an entropy index to several functions, including Species Richness, Simpson, Quadratic, and Berger-Parker indexes to quantify the diversity, uncertainty, or randomness of a system, respectively. Among these, 
Simpson's diversity and Shannon's entropy indices have already been applied to analyze TCR sequence data. A comparative review of such scoring strategies was published by Miqueu et al. (2007). Deep sequencing repertoire analysis calls for advanced statistical analysis and graphical representations, such as multivariate analysis (e.g., hierarchical clustering, principal component analysis, multidimensional scaling, etc.) and probabilistic or network modeling of sequence distributions (Mora et al., 2010; Ben-Hamo and Efroni, 2011; Murugan et al., 2012). In this perspective, different parameters can be computed to quantify the differences between repertoires at distinct levels. An important feature is the total diversity of the repertoire, which can be estimated from a dataset following approaches (Fisher et al., 1943; Efron and Thisted, 1976). At another level, a deep sequencing dataset can be summarized in various groups of sequences sharing common features (e.g., $\mathrm{V}$ or J gene segment, CDR3 length, sample origin, frequency), which allows comparisons between different conditions. For example, a perturbation score can be computed from the Hamming distance (Gorochov et al., 1998) to compare antibody repertoires between infected fish and a reference from control animals.

\section{EFFECT OF TEMPERATURE ON FISH B CELL RESPONSES}

While fish have colonized aquatic environments across a wide temperature range, only a few species control their internal temperature. The adaptation of fish immune system to various temperature is not fully understood, but the magnitude of the

\section{REFERENCES}

Abelli, L., Picchietti, S., Romano, N., Mastrolia, L., and Scapigliati, G. (1997). Immunohistochemistry of gut-associated lymphoid tissue of the sea bass Dicentrarchus labrax (L.). Fish Shellish Immunol. $7,235$.

Ademokun, A., Wu, Y., Martin, V., Mitra, R., Sack, U., Baxendale, H., et al. (2011). Vaccination-induced changes in human B-cell repertoire and pneumococcal IgM and IgA antibody at different ages. Aging Cell $10,922-930$

Aparicio, S., Chapman, J., Stupka, E., Putnam, N., Chia, J.-M., Dehal, P., et al. (2002). Whole-genome shotgun assembly and analysis of the genome of Fugu rubripes. Science 297, 1301-1310.

Bao, Y., Wang, T., Guo, Y., Zhao, Z., Li, N., and Zhao, Y. (2010). The immunoglobulin gene loci in the teleost Gasterosteus aculeatus. Fish Shellfish Immunol. 28, $40-48$.

Barreto, V. M., Pan-Hammarstrom, Q., Zhao, Y., Hammarstrom, L., Misulovin, Z., and Nussenzweig, M. C. (2005). AID from bony fish catalyses call switch recombination. J. Exp. Med. 202, 733.

Bartl, S., Miracle, A. L., Rumfelt, L. L., Kepler, T. B., Mochon, E., Litman, G. W., et al. (2003). Terminal deoxynucleotidyl transferases from elasmobranchs reveal structural conservation within vertebrates. Immunogenetics 55, 594-604.

Beetz, S., Diekhoff, D., and Steiner, L. A. (2007). Characterization of terminal deoxynucleotidyl transferase and polymerase mu in zebrafish. Immunogenetics 59, 735-744.

Bengtén, E., Leanderson, T., and Pilström, L. (1991). Immunoglobulin heavy chain cDNA from the teleost Atlantic cod (Gadus morhua L.): nucleotide sequences of secretory and membrane form show an unusual splicing pattern. Eur. J. Immunol. 21, 3027-3033.

Bengtén, E., Quiniou, S., Hikima, J., and Waldbieser, G. (2006). Structure of the catfish IGH locus: analysis of the region including the single functional IGHM gene. Immunogenetics $58,831-844$.

Ben-Hamo, R., and Efroni, S. (2011). B cell repertoire from Zebrafish self-organizes into distinct network features. BMC Syst. Biol. 5:27. doi:10.1186/1752-0509-5-27

Bladen, C. L., Navarre, S., Dynan, W. S., and Kozlowski, D. J. (2007). Expression of the Ku70 subunit (XRCC6) and protection from low dose ionizing radiation during zebrafish embryogenesis. Neurosci. Lett. 422, 97-102. The whole-organism heavy chain

primary response to $\mathrm{T}$ dependent antigens is suppressed at lower temperatures for example in the channel catfish (Bly and Clem, 1991) and carp (Le Morvan et al., 1996). More recently, it was also observed that the highest magnitude of rainbow trout specific IgM - but not IgT - response against Yersinia ruckeri was obtained at high temperature $\left(25^{\circ} \mathrm{C}\right.$; Raida and Buchmann, 2007). Differential sensitivity of lymphocyte responses to temperature variations may affect immune repertoires - perhaps especially regarding natural antibodies and mucosal locations - since different pathogens may be adapted to distinct temperature ranges.

With a large number of species and a wide diversity of anatomy, physiological, and ecological adaptations to the aquatic environments and their pathogens, fish offer interesting perspectives for comparative analysis of B cell repertoire biology. New sequencing technologies have already made it possible.

\section{ACKNOWLEDGMENTS}

This work was supported by Institut National de la Recherche Agronomique and the European Community's Seventh Framework Program (FP7/2007-2013) under Grant Agreement 222719 LIFECYCLE and by the European Commission under the Work Programme 2012 of the seventh Framework Programme for Research and Technological Development of the European Union (Grant Agreement 311993 TARGETFISH). We acknowledge Dr. Oystein Evensen for helpful discussions and Dr. Vicky Lampropoulou for critical reading of the manuscript.

Bly, J. E., and Clem, L. W. (1991) Temperature-mediated processes in teleost immunity: in vitro immunosuppression induced by in vivo low temperature in channel catfish. Vet. Immunol. Immunopathol. 28, 365-377.

Bousso, P., Casrouge, A., Altman, J. Haury, M., Kanellopoulos, J., Abastado, J.-P., et al. (1998). Individual variations in the murine $\mathrm{T}$ cell response to a specific peptide reflect variability in naive repertoires. Immunity 9, 169-178.

Bromage, E. S., Kaattari, I. M., Zwollo, P., and Kaattari, S. L. (2004). Plasmablast and plasma cell production and distribution in trout immune tissues. J. Immunol. 173, 7317-7323.

Castro, R., Jouneau, L., Pham, H.P., Bouchez, O., Giudicelli, V., Lefranc, M.-P., et al. (2013). Teleost fish mount complex clonal $\operatorname{IgM}$ and $\operatorname{IgT}$ responses in spleen upon systemic viral infection. PLoS Pathog. 9:e1003098. doi: 10.1371/journal.ppat.1003098

Collette, A., and Six, A. (2002). ISEApeaks: an Excel platform for GeneScan and Immunoscope data retrieval, management and analysis. Bioinformatics 18, 329-330.

Coscia, M. R., and Oreste, U. (2003). Limited diversity of the immunoglobulin heavy chain variable domain of the emerald rockcod Trematomus bernacchii. Fish Shellfish Immunol. 14, 71-92.

Coscia, M. R., Varriale, S., De Santi, C., Giacomelli, S., and Oreste, U. (2010). Evolution of the Antarctic teleost immunoglobulin heavy chain gene. Mol. Phylogenet. Evol. 55, 226-233.

Criscitiello, M. F., and Flajnik, M. F. (2007). Four primordial immunoglobulin light chain isotypes, including lambda and kappa, identified in the most primitive living jawed vertebrates. Eur. J. Immunol. 37, 2683-2694.

Daggfeldt, A., Bengtén, E., and Pilström, L. (1993). A cluster type organization of the loci of the immunoglobulin light chain in Atlantic cod (Gadus morhua L.) and rainbow trout (Oncorhynchus mykiss Walbaum) indicated by nucleotide sequences of cDNAs and hybridization analysis. Immunogenetics 38, 199-209.

Danilova, N., Bussmann, J., Jekosch, K., and Steiner, L. A. (2005). The immunoglobulin heavy-chain locus in zebrafish: identification and expression of a previously unknown isotype, immunoglobulin Z. Nat. Immunol. 6, 295-302.

Danilova, N., and Steiner, L. A. (2002). $B$ cells develop in the zebrafish pancreas. Proc. Natl. Acad. Sci. U.S.A.99, 13711-13716. 
Edholm, E.-S., Bengtén, E., Stafford, J. L., Sahoo, M., Taylor, E. B., Miller, N. W., et al. (2010). Identification of two $\mathrm{IgD}+\mathrm{B}$ cell populations in channel catfish, Ictalurus punctatus. J. Immunol. 185, 4082-4094.

Edholm, E.-S., Wilson, M., Sahoo, M., Miller, N. W., Pilström, L., Wermenstam, N. E., et al. (2009). Identification of Igsigma and Iglambda in channel catfish, Ictalurus punctatus, and Iglambda in Atlantic cod, Gadus morhua. Immunogenetics 61, 353-370.

Efron, B., and Thisted, R. (1976). Estimating the number of unseen species: how many words did Shakespeare know? Biometrika 63, 435-447.

Espelid, S., Rødseth, O., and Jørgensen, T. (1991). Vaccination experiments and studies of the humoral immune responses in cod, Gadus morhua L., to four strains of monoclonal defined Vibrio anguillarum. J. Fish Dis. 14, 185-198.

Fisher, R. A., Steven-Corbet, A., and Williams, C. B. (1943). The relation between the number of species and the number of individuals in a random sample of an animal population. J. Anim. Ecol. 12, 42-58.

Flajnik, M. F., and Kasahara, M. (2009). Origin and evolution of the adaptive immune system: genetic events and selective pressures. Nat. Rev. Genet. $11,47-59$.

Gambón-Deza, F., Sánchez-Espinel, C., and Magadán-Mompó, S. (2010). Presence of an unique $\operatorname{IgT}$ on the IGH locus in three-spined stickleback fish (Gasterosteus aculeatus) and the very recent generation of a repertoire of VH genes. Dev. Comp. Immunol. 34, 114-122.

Ghaffari, S. H., and Lobb, C. J. (1993). Structure and genomic organization of immunoglobulin light chain in the channel catfish. An unusual genomic organizational pattern of segmental genes. J. Immunol. 151, 6900-6912.

Ghaffari, S. H., and Lobb, C. J. (1997). Structure and genomic organization of a second class of immunoglobulin light chain genes in the channel catfish. J. Immunol. 159, 250-258.

Gorochov, G., Neumann, A. U., Kereveur, A., Parizot, C., Li, T., Katlama, C., et al. (1998). Perturbation of CD4+ and CD8+ T-cell repertoires during progression to AIDS and regulation of the CD4+ repertoire during antiviral therapy. Nat. Med. 4, 215-221.

Greenhalgh, P., and Steiner, L. A. (1995). Recombination activating gene 1 (Rag1) in zebrafish and shark. Immunogenetics 41, 54-55.

Guo, Y., Bao, Y., Wang, H., Hu, X., Zhao, Z., Li, N., et al. (2011). A Preliminary analysis of the immunoglobulin genes in the African elephant (Loxodonta africana). PLoS ONE 6:e16889. doi:10.1371/journal.pone.0016889

Hansen, J., Landis, E., and Phillips, R. (2005). Discovery of a unique Ig heavy-chain isotype (IgT) in rainbow trout: implications for a distinctive B cell developmental pathway in teleost fish. Proc. Natl. Acad. Sci. U.S.A. 102, 6919-6924.

Hansen, J. D. (1997). Characterization of rainbow trout terminal deoxynucleotidyl transferase structure and expression. TdT and RAG1 coexpression define the trout primary lymphoid tissues. Immunogenetics $46,367-375$.

Hansen, J. D., and Kaattari, S. L. (1995). The recombination activation gene 1 (RAG1) of rainbow trout (Oncorhynchus mykiss): cloning, expression, and phylogenetic analysis. Immunogenetics 42 , 188-195.

Hansen, J. D., and Kaattari, S. L. (1996). The recombination activating gene 2 (RAG2) of the rainbow trout Oncorhynchus mykiss. Immunogenetics 44, 203-211.

Hayman, J. R., and Lobb, C. J. (2000). Heavy chain diversity region segments of the channel catfish: structure, organization, expression and phylogenetic implications. $J$. Immunol. 164, 1916-1924.

Henkel, C. V., Dirks, R. P., Jansen, H. J., Forlenza, M., Wiegertjes, G. F., Howe, K., et al. (2012). Comparison of the exomes of common carp (Cyprinus carpio) and zebrafish (Danio rerio). Zebrafish 9, 59-67.

Hirono, I., Nam, B.-H., Enomoto, J., Uchino, K., and Aoki, T. (2003). Cloning and characterisation of a cDNA encoding Japanese flounder Paralichthys olivaceus IgD. Fish Shellfish Immunol. 15, 63-70.

Hordvik, I. (2002). Identification of a novel immunoglobulin delta transcript and comparative analysis of the genes encoding IgD in Atlantic salmon and Atlantic halibut. Mol. Immunol. 39, 85-91.

Hordvik, I., Thevarajan, J., Samdal, I., Bastani, N., and Krossøy, B. (1999). Molecular cloning and phylogenetic analysis of the Atlantic salmon immunoglobulin D gene. Scand. J. Immunol. 50, 202-210.

Hu, Y.-L., Zhu, L.-Y., Xiang, L.-X., and Shao, J.-Z. (2011). Discovery of an unusual alternative splicing pathway of the immunoglobulin heavy chain in a teleost fish, Danio rerio. Dev. Comp. Immunol. 35, 253-257.

Huang, T., Zhang, M., Wei, Z. Wang, P., Sun, Y., Hu, X., et al. (2012). Analysis of immunoglobulin transcripts in the ostrich Struthio camelus, a primitive avian species. PLoS ONE 7:e34346. doi:10.1371/journal.pone.0034346

Jerne, N. K. (1972). "What precedes clonal selection? Ontogeny of acquired immunity," in Proceedings of the A CIBA Foundation Symposium 1971, Amsterdam, 1-15.

Jiang, N., Weinstein, J. A., Penland, L., White, R. A., and Fisher, D. S. (2011) Determinism and stochasticity during maturation of the zebrafish antibody repertoire. Proc. Natl. Acad. Sci. U.S.A. 108, 5348-5353.

Jones, F. C., Grabherr, M. G., Chan, Y. F., Russell, P., Mauceli, E., Johnson, J., et al. (2012). The genomic basis of adaptive evolution in threespine sticklebacks. Nature 484, 55-61.

Kasahara, M., Naruse, K., Sasaki, S., Nakatani, Y., Qu, W., Ahsan, B., et al. (2007). The medaka draft genome and insights into vertebrate genome evolution. Nature 447, 714-719.

Kato, L., Begum, N. A., Maxwell Burroughs, A., Doi, T., Kawaib, J., Daubb, C. O., et al. (2011). Nonimmunoglobulin target loci of activation-induced cytidine deaminase (AID) share unique features with immunoglobulin genes. Proc Natl. Acad. Sci. U.S.A. 109, 2479.

Kitamura, D., Kudo, A., Schaal, S. Müller, W., Melchers, F., and Rajewsky, K. (1992). A critical role of lambda 5 protein in B cell development. Cell 69, 823-831.

Koppang, E. O., Bjerkås, I., Haugarvoll, E., Chan, E. K. L., Szabo, N. J., Ono, N., et al. (2008). Vaccinationinduced systemic autoimmunity in farmed Atlantic salmon. J. Immunol. 181, 4807-4814

Lam, S. H., Chua, H. L., Gong, Z., Lam, T. J., and Sin, Y. M. (2004). Development and maturation of the immune system in zebrafish, Danio rerio: a gene expression profiling, in situ hybridization and immunological study. Dev. Comp. Immunol. 28, 9-28.

Le Morvan, C., Deschaux, P., and Troutaud, D. (1996). Effects and mechanisms of environmental temperature on carp (Cyprinus carpio) anti-DNP antibody response and non-specific cytotoxic cell activity: a kinetic study. Dev. Comp. Immunol. 20, 331-340.
Lee, M. A., Bengtén, E., Daggfeldt, A., Rytting, A. S., and Pilström, L. (1993). Characterisation of rainbow trout cDNAs encoding a secreted and membrane-bound Ig heavy chain and the genomic intron upstream of the first constant exon. Mol. Immunol. 30, 641-648.

Lee, S. S., Tranchina, D., Ohta, 3Y., Flajnik, M. F., and Hsu, E. (2002). Hypermutation in shark immunoglobulin light chain genes results in contiguous substitutions. Immunity 16, 571.

Lin, M. Y., and Welsh, R. M. (1998). Stability and diversity of T cell receptor repertoire usage during lymphocytic choriomeningitis virus infection of mice. J. Exp. Med. 188, 1993-2005.

Lundqvist, M., Strömberg, S., Bouchenot, C., Pilström, L., and Boudinot, P. (2009). Diverse splicing pathways of the membrane IgHM pre-mRNA in a Chondrostean, the Siberian sturgeon. Dev. Comp. Immunol. 33, 507-515.

Lundqvist, M. L., Middleton, D. L., Hazard, S., and Warr, G. W. (2001) The immunoglobulin heavy chain locus of the duck. Genomic organization and expression of $\mathrm{D}, \mathrm{J}$, and $\mathrm{C}$ region genes. J. Biol. Chem. 276, 46729-46736.

Magadán-Mompó, S., Sánchez-Espinel, C., and Gambón-Deza, F. (2011). Immunoglobulin heavy chains in medaka (Oryzias latipes). BMC Evol. Biol. 11:165. doi:10.1186/14712148-11-165

Magnadottir, B., Jonsdottir, H., Helgason, S., Bjoörnson, B., Solem, S., and Pilström, L. (2001). Immune parameters of immunised cod. Fish Shellish Immunol. 10, 75-89.

Malecek, K., Lee, V., Feng, W., Huang, J. L., Flajnik, M. F., Ohta, Y. et al. (2008). Immunoglobulin heavy chain exclusion in the shark. PLoS Biol. 6:e157. doi:10.1371/journal.pbio.0060157

Marianes, A. E., and Zimmerman, A. M. (2011). Targets of somatic hypermutation within immunoglobulin light chain genes in zebrafish. Immunology 132, 240-255.

Matsumoto, M., Lo, S. F., Carruthers, C. J., Min, J., Mariathasan, S., Huang, G., et al. (1996). Affinity maturation without germinal centres in lymphotoxin-alpha-deficient mice. Nature 382, 462-466.

Miqueu, P., Guillet, M., Degauque, N., and Dor, J. (2007). Statistical analysis of CDR3 length distributions for the assessment of $\mathrm{T}$ and $\mathrm{B}$ cell repertoire biases. Mol. Immunol. 44 1057-1064 
Mora, T., Walczak, A. M., Bialek, W., and Callan, C. G. (2010). Maximum entropy models for antibody diversity. Proc. Natl. Acad. Sci. U.S.A. 107, 5405-5410.

Murugan, A., Mora, T., Walczak, A. M., and Callan, C. G. (2012). Statistical inference of the generation probability of T-cell receptors from sequence repertoires. Proc. Natl. Acad. Sci. U.S.A. 109, 16161-16166.

Ohta, Y., and Flajnik, M. (2006). IgD, like $\mathrm{IgM}$, is a primordial immunoglobulin class perpetuated in most jawed vertebrates. Proc. Natl. Acad. Sci. U.S.A. 103, 10723-10728.

Pannetier, C., Cochet, M., Darche, S., Casrouge, A., Zöller, M., and Kourilsky, P. (1993). The sizes of the CDR3 hypervariable regions of the murine $\mathrm{T}$-cell receptor beta chains vary as a function of the recombined germline segments. Proc. Natl. Acad. Sci. U.S.A. 90, 4319-4323.

Pannetier, C., Even, J., and Kourilsky, P. (1995). T-cell repertoire diversity and clonal expansions in normal and clinical samples. Immunol. Today 16, 176-181.

Partula, S., Schwager, J., Timmusk, S., Pilström, L., and Charlemagne, J. (1996). A second immunoglobulin light chain isotype in the rainbow trout. Immunogenetics 45 , 44-51.

Pilström, L., and Petersson, A. (1991). Isolation and partial characterization of immunoglobulin from cod (Gadus morhua L.). Dev. Comp. Immunol. 15, 143-152.

Raida, M. K., and Buchmann, K. (2007). Temperature-dependent expression of immune-relevant genes in rainbow trout following Yersinia ruckeri vaccination. Dis. Aquat. Org. 77, 41-52.

Ramirez-Gomez, F., Greene, W., Rego, K., Hansen, J. D., Costa, G., Kataria, P., et al. (2012). Discovery and characterization of secretory $\operatorname{IgD}$ in rainbow trout: secretory $\operatorname{IgD}$ is produced through a novel splicing mechanism. J. Immunol. 188, 1341-1349.

Razquin, B., Castillo, A., Lopez-Fierro, P., Alvarez, F., Zapata, A., and Villena, A. (1990). Ontogeny of IgMproducing cells in the lymphoid organs of rainbow trout, Salmo gairdneri Richardson: an immunological and enzyme-histochemical study. J. Fish Biol. 36, 159.

Rombout, J. H., Taverne-Thiele, A. J., and Villena, M. I. (1993). The gutassociated lymphoid tissue (GALT) of carp (Cyprinus carpio L.): an immunocytochemical analysis. Dev. Comp. Immunol. 17, 55-66.
Ryo, S., Wijdeven, R. H. M., Tyagi, A., Hermsen, T., Kono, T., Karunasagar, I., et al. (2010). Common carp have two subclasses of bonyfish specific antibody IgZ showing differential expression in response to infection. Dev. Comp. Immunol. 34, 1183-1190.

Saha, N. R., Suetake, H., Kikuchi, K., and Suzuki, Y. (2004). Fugu immunoglobulin D: a highly unusual gene with unprecedented duplications in its constant region. Immunogenetics 56, 438-447.

Salinas, I., Zhang, Y.-A., and Sunyer, J. O. (2011). Mucosal immunoglobulins and B cells of teleost fish. Dev. Comp. Immunol. 35, 1346-1365.

Saunders, H. L., Oko, A. L., Scott, A. N., Fan, C. W., and Magor, B. G. (2010). The cellular context of AID expressing cells in fish lymphoid tissues. Dev. Comp. Immunol. 34, 669.

Savan, R., Aman, A., Nakao, M., Watanuki, H., and Sakai, M. (2005). Discovery of a novel immunoglobulin heavy chain gene chimera from common carp (Cyprinus carpio L.). Immunogenetics 57, 458-463.

Schorpp, M., Bialecki, M., Diekhoff, D., Walderich, B., Odenthal, J., Maischein, H.-M., et al. (2006). Conserved functions of Ikaros in vertebrate lymphocyte development: genetic evidence for distinct larval and adult phases of $\mathrm{T}$ cell development and two lineages of $\mathrm{B}$ cells in zebrafish. J. Immunol. 177, 2463-2476.

Schrøder, M., Espelid, S., and Jørgensen, T. (1992). Two serotypes of Vibrio salmonicida isolated from diseased cod (Gadus morhua L.); virulence immunological studies and vaccination experiments. Fish Shellfish Immunol. 2, 211-221.

Smelty, P., Marchal, C., Renard, R., Sinzelle, L., Pollet, N., Dunon, D., et al. (2010). Identification of the pre$\mathrm{T}$-cell receptor alpha chain in nonmammalian vertebrates challenges the structure-function of the molecule. Proc. Natl. Acad. Sci. U.S.A. 107, 19991-19996.

Srisapoome, P., Ohira, T., Hirono, I., and Aoki, T. (2004). Genes of the constant regions of functional immunoglobulin heavy chain of Japanese flounder, Paralichthys olivaceus. Immunogenetics 56, 292-300.

Star, B., Nederbragt, A. J., Jentoft, S., Grimholt, U., Malmstrøm, M., Gregers, T. F., et al. (2011). The genome sequence of Atlantic cod reveals a unique immune system. Nature 477, 207-210.
Stenvik, J., and Jørgensen, T. Ø. (2000). Immunoglobulin D (IgD) of Atlantic cod has a unique structure. 51, 452-461.

Stenvik, J., Schrøder, M., Olsen, K., Zapata, A., and Jørgensen, T. (2001). Expression of immunoglobulin heavy chain transcripts $(\mathrm{VH}-$ families, IgM, and IgD) in head kidney and spleen of the Atlantic cod (Gadus morhua L.). Dev. Comp. Immunol. 25, 291-302.

Timmusk, S., Partula, S., and Pilström, L. (2000). Different genomic organization and expression of immunoglobulin light-chain isotypes in the rainbow trout. Immunogenetics 51, 905-914.

Trede, N. S., Langenau, D. M., Traver, D., Look, A. T., and Zon, L. I. (2004). The use of zebrafish to understand immunity. Immunity 20 , 367-379.

van Ginkel, F. W., Miller, N. W., Cuchens, M. A., and Clem, L. W. (1994). Activation of channel catfish B cells by membrane immunoglobulin crosslinking. Dev. Comp. Immunol. 18, 97-107.

Vela, J. L., Aït-Azzouzene, D., Duong, B. H., Ota, T., and Nemazee, D. (2008). Rearrangement of mouse immunoglobulin kappa deleting element recombining sequence promotes immune tolerance and lambda B cell production. Immunity 28, 161-170.

Wang, X., Olp, J. J., and Miller, R. D. (2009). On the genomics of immunoglobulins in the gray, short-tailed opossum Monodelphis domestica. Immunogenetics 61 , 581-596.

Weill, J.-C., Weller, S., and Reynaud, C.A. (2009). Human marginal zone B cells. Annu. Rev. Immunol. 27, 267-285.

Weinstein, J. a, Jiang, N., White, R. a, Fisher, D. S., and Quake, S. R. (2009). High-throughput sequencing of the zebrafish antibody repertoire. Science 324, 807-810.

Wienholds, E., Schulte-Merker, S. Walderich, B., and Plasterk, R. H. A. (2002). Target-selected inactivation of the zebrafish ragl gene. Science 297, 99-102.

Willett, C. E., Cherry, J. J., and Steiner, L. A. (1997). Characterization and expression of the recombination activating genes (rag1 and rag2) of zebrafish. Immunogenetics 45, 394-404.

Wilson, M., Bengtén, E., Miller, N. W., Clem, L. W., Du Pasquier, L., and Warr, G. W. (1997). A novel chimeric Ig heavy chain from a teleost fish shares similarities to IgD.
Proc. Natl. Acad. Sci. U.S.A. 94, 4593-4597.

Wilson, M., Hsu, E., Marcuz, A., Courtet, M., Du Pasquier, L., and Steinberg, C. (1992). What limits affinity maturation of antibodies in Xenopus-the rate of somatic mutation or the ability to select mutants? EMBO J. 11, 4337-4347.

Wilson, M. R., van Ravenstein, E., Miller, N. W., Clem, L. W., Middleton, D. L., and Warr, G. W. (1995a). cDNA sequences and organization of IgM heavy chain genes in two holostean fish. Dev. Comp. Immunol. 19, 153-164.

Wilson, M., Ross, D., Miller, N., Clem, L., Middleton, D., and Warr, G. (1995b). Alternate pre-mRNA processing pathways in the production of membrane IgM heavy chains in holostean fish. Dev. Comp. Immunol. 19, 165-177.

Xiao, F. S., Wang, Y. P., Yan, W., Chang, M. X., Yao, W. J., Xu, Q. Q., et al. (2010). Ig heavy chain genes and their locus in grass carp Ctenopharyngodon idella. Fish Shellfish Immunol. 29, 594-599.

Yang, F., Waldbieser, G. C., and Lobb, C. J. (2006). The nucleotide targets of somatic mutation and the role of selection in immunoglobulin heavy chains of a teleost fish. J. Immunol. 176, 1655.

Yasuike, M., Boer, J. D., Schalburg, K. R. V., Cooper, G. A., McKinnel, L., Messmer, A., et al. (2010). Evolution of duplicated IgH loci in Atlantic salmon, Salmo salar. BMC Genomics 11:486. doi:10.1186/1471-2164-11486

Ye, J., Kaattari, I. M., and Kaattari, S. L. (2011). The differential dynamics of antibody subpopulation expression during affinity maturation in a teleost. Fish Shellfish Immunol. 30, 372-377.

Zapata, A., Diez, B., Cejalvo, T. Gutiérrez-de Frías, C., and Cortés, A. (2006). Ontogeny of the immune system of fish. Fish Shellfish Immunol. 20, 126-136.

Zhang, Y., Salinas, I., Li, J., Parra, D., Bjork, S., Xu, Z., et al. (2010). IgT, a primitive immunoglobulin class specialized in mucosal immunity. Nat. Immunol. 11, 827-835.

Zhao, Y., Kacskovics, I., Pan, Q., Liberles, D. A., Geli, J., Davis, S. K., et al. (2002). Artiodactyl IgD: the missing link. J. Immunol. 169, 4408-4416.

Zhao, Y., Pan-Hammarström, Q., Kacskovics, I., and Hammarström, L. (2003). The porcine Ig delta gene: unique chimeric splicing of the first constant region domain in its heavy 
chain transcripts. J. Immunol. 171, 1312-1318.

Zhao, Y., Rabbani, H., Shimizu, A., and Hammarström, L. (2000). Mapping of the chicken immunoglobulin heavy-chain constant region gene locus reveals an inverted alpha gene upstream of a condensed upsilon gene. Immunology 101, 348-353.

Zimmerman, A. M., Romanowski, K. E., and Maddox, B. J. (2011). Targeted annotation of immunoglobulin light chain ( $\operatorname{IgL})$ genes in zebrafish from BAC clones reveals kappa-like recombining/deleting elements within IgL constant regions. Fish Shellfish Immunol. 31, 697-703.

Zimmerman, A. M., Yeo, G., Howe, K., Maddox, B. J., and Steiner, L. A. (2008). Immunoglobulin light chain (IgL) genes in zebrafish: genomic configurations and inversional rearrangements between (V(L)-J(L)-C(L)) gene clusters. Dev. Comp. Immunol. 32, 421-434.

Zwollo, P. (2011). Dissecting teleost B cell differentiation using transcription factors. Dev. Comp. Immunol. 35, 898-905.

Zwollo, P., Cole, S., Bromage, E., and Kaattari, S. (2005). B cell heterogeneity in the teleost kidney: evidence for a maturation gradient from anterior to posterior kidney. $J$. Immunol. 174, 6608-6616.

Conflict of Interest Statement: The authors declare that the research was conducted in the absence of any commercial or financial relationships that could be construed as a potential conflict of interest.

Received: 18 December 2012; paperpending published: 06 January 2013; accepted: 24 January 2013; published online: 13 February 2013.

Citation: Fillatreau S, Six A, Magadan $S$, Castro R, Sunyer JO and Boudinot
$P$ (2013) The astonishing diversity of Ig classes and B cell repertoires in teleost fish. Front. Immun. 4:28. doi: 10.3389/fimmu.2013.00028

This article was submitted to Frontiers in B Cell Biology, a specialty of Frontiers in Immunology.

Copyright $\odot 2013$ Fillatreau, Six, Magadan, Castro, Sunyer and Boudinot. This is an open-access article distributed under the terms of the Creative Commons Attribution License, which permits use, distribution and reproduction in other forums, provided the original authors and source are credited and subject to any copyright notices concerning any third-party graphics etc. 